\title{
Study of the Local Universities Non-Dr. Young Teachers scientific Research Cultivation Based on the Two-factor Theory: Jiujiang University as an Example
}

\author{
Haiyan WANG \\ Jiujiang University, Jiangxi, China
}

\begin{abstract}
Dr Local University how to train the young teachers' scientific research ability, inspire the teachers' scientific research enthusiasm is the school teaching and research to the enterprise sustainable development is an important work. Two-factor theory offers a new way for the work, through the effective use of motivation factors and hygiene factors, reasonable to meet their needs, and can better develop their scientific research ability, young teachers are more full utilized3 creativity, realize the sustainable development of the school.
\end{abstract}

KEYWORD: local colleges; Two-factor theory; The Dr Young teachers; Scientific research consciousness

Two-factor theory is called the "incentive a hygiene factors theory", in 1959 the famous American management scientist Frederick Herzberg (Fredrick Herzberg) is put forward. The theory proposed has two sides. One side is relatively fixed, have health care function, policy, management system, mainly including work supervision measures, interpersonal relationships, wages, benefits and other basic conditions. When these factors exceeds the acceptable level of the people, can produce dissatisfied with work. However, when people think of these factors is very good, it can eliminate not only satisfied, will not bring positive work attitude and this produces some not satisfied, nor unsatisfied in the middle of the state. The other side is often change, has the incentive effect. Mainly includes the work achievement, recognition, has given the leadership of the challenging work, take more

responsibilities, and other personal growth and development opportunities. If these factors have, you can for people to produce larger, more effective, more lasting motivation. Fredrick Herzberg argues that managers should realize that hygiene factors are necessary, but it once was not satisfied with offset, also will not be able to produce more positive effect, only "incentives" will bring better performance [1]. Into the young teachers' scientific research consciousness cultivation path research process, main is to cultivate path is divided into two parts, basic guarantee and incentive behavior research.

Scientific research ability is a kind of advanced, from the education practice and beyond the ability to innovate and sublimation. Scientific research is essential diathesis for education workers in the new period, has become the modern teacher, especially the ability of young teachers' basic connotation. According to statistics, the Nobel prizewinners "creative age" is the best age area between $30 \sim 50$ years old, including $31 \sim 45,15$ years is the golden age of their results in [1]. This determines the middle-aged and young teachers in colleges and universities teacher group in the process of knowledge innovation have active thinking that one of the most effective quality, through the scientific research activities, the traditional passive and dependent, repetitive type teaching method into active model, innovative teaching modes, guides the student to explore spirit [2]. Paper referred to in the "not" Dr. Young teachers group is under the age of 45 , and the following degree or master degree, associate professor, and the following titles of teachers. Such groups occupy most of the proportion, in ordinary colleges and universities play an important role in college teaching. But at the same time this kind of teacher is in the act of all kinds of scientific research in a relatively weak position.

\section{THE ANALYSIS OF THE SITUATION}

Local colleges and universities is a kind of is located in the general city, its research strength is very weak from "985" and "211" key universities, but also carry the heavy task of personnel training in colleges and universities. Jiujiang university is a place to fouryear-undergraduate universities in the newly merged 
in 2002, the school has 1830 full-time teachers, including the subtropical high above title 721 people, 1243 people doctor, master's degree; The postgraduate 57 people; Colleges and universities in jiangxi province 44 people such as discipline leaders and the backbone of middle-aged and young teachers; Jiangxi province colleges and universities teacher 6 people; In jiangxi province "pacesetter project" the first and second level candidate 13 people, including young teachers possess all the teachers $83.36 \%$ (see table 1). The school in $2009 \sim 2012$ national projects (mainly refers to the national natural science foundation, national social science fund, the national education science plan, etc.) project has a bigger breakthrough, of which 2009 project for 4 items, project for 11, 2010, 2012 to 16; Dr Compared to the youth group in which teachers share is small, but the overall rise, to $0 \%$ in $2009,10 \%$ in 2010 and 2011 was $9 \%, 12.5 \%$ in 2012.

Table 1: Statistical Analysis of full-time teachers school

\begin{tabular}{|c|c|c|c|c|c|c|c|}
\hline \multicolumn{8}{|c|}{ Professional titles } \\
\hline \multicolumn{2}{|c|}{ Professor } & \multicolumn{2}{|c|}{$\begin{array}{l}\text { associate } \\
\text { professor }\end{array}$} & \multicolumn{2}{|c|}{ lecture } & \multicolumn{2}{|c|}{ primary } \\
\hline num & pro\% & num & pro\% & num & pro\% & num & pro\% \\
\hline 132 & 7.27 & 487 & 26.83 & 949 & 52.29 & 247 & 13.61 \\
\hline \multicolumn{8}{|c|}{ Degree } \\
\hline \multicolumn{2}{|l|}{ DR. } & \multicolumn{2}{|c|}{ master's } & \multicolumn{2}{|c|}{ Degree } & \multicolumn{2}{|c|}{ Non-degree } \\
\hline num & pro\% & num & pro\% & num & pro\% & num & pro\% \\
\hline 96 & 5.29 & 990 & 51.70 & 715 & 39.39 & 14 & 3.62 \\
\hline \multicolumn{8}{|c|}{ Age structure } \\
\hline \multicolumn{2}{|l|}{$\leq 35$} & \multicolumn{2}{|c|}{$36-45$} & \multicolumn{2}{|c|}{$46-55$} & \multicolumn{2}{|l|}{$\geq 56$} \\
\hline num & pro\% & num & pro\% & num & pro\% & num & pro\% \\
\hline 1003 & 55.26 & 510 & 28.10 & 270 & 14.88 & 32 & 1.76 \\
\hline
\end{tabular}

\section{DR. YOUNG TEACHERS IN COLLEGES AND UNIVERSITIES SCIENTIFIC RESEARCH CONSCIOUSNESS OF EXISTENCE PROBLEM ANALYSIS BASED ON THE TWO-FACTOR THEORY}

University of Dr. Young teachers are widespread scientific research consciousness is weak, research atmosphere is not strong. Scientific research funds inadequacy, scientific research and less time. Fewer backbone, to academic echelon construction, etc. Also there's sort of young teachers' scientific research ability and scientific research environment is not optimistic, [3] remains to be further improved.
3 DR. YOUNG TEACHERS IN COLLEGES AND UNIVERSITIES SCIENTIFIC RESEARCH CONSCIOUSNESS CULTIVATION PATH ANALYSIS BASED ON THE THEORY OF DOUBLE FACTORS

\section{1 pay attention to hygiene factors, completes the basic part of the scientific research consciousness}

(1) the professional basic conditions optimized. Hygiene factors include living environment health care and basic health care professional two parts. The living environment factor as the external condition, difficult to make big changes due to the individual; Belong to the professional basic conditions for the internal factors, is a hard part, is to break through. In optimization professional basic conditions in terms of "sanduo" can be effort: more than one is summary, conclusion was the forerunner of innovation, is the foundation of the innovative thought. Can use at ordinary times, browsing the web, literature view and other daily work process, exercise their ability to summarize, and record the good shine; At the same time pay more attention to writing all kinds of paper, to improve ability to summarize. Summary, and summarized; Have summarized, there will be improved. Second, more participation, actively participate in more mature team, improve their scientific literacy, way of thinking to learn scientific research workers. More than three is to declare: it is necessary to increase the experience of project application, each declaration is a improve scientific research consciousness. Notice to declare all levels of various projects (such as field, departmental level and provincial level, etc.) projects, constantly improve their consciousness of scientific research in the project practice and summarizes the innovation ability, don't cry because it is afraid of not afraid to write, also don't write because of no don't, only wrote organic meeting, if you don't write, think no chance.

(2) active in academic exchanges, and invited experts to guide. Academic communication is essential for young teachers to grow. Academic exchanges for a young scholar, is not only the process, to show their research results and share the process of scientific research achievements and failures. Young teachers can obtain new revelation, in exchange for new ideas. At the same time should also pay attention to communication with both internal and external field experts and consult. Can ask an expert to help their chosen research direction, or even to join the field research; Invite the expert help refine scientific problems in the inherent research direction. 


\subsection{Strengthen incentive factors, establish the consciousness of scientific research, focus on high quality projects.}

Should have in front of the relatively high level scientific research project "dare to strong-arm reaction,, sharp-toothed way of doing things, Lou hide form, line can be in the" spirit of broken cocoon, do want to declare, think of what, why, how.

(1) to establish a correct attitude. One is set to participate in state of mind. Actively declare, overcome dare not, cannot state of mind. At present domestic most topics including national social science fund (since), etc., all have no clear requirements highly educated or high professional titles, lecturer, master as long as there are two peer experts recommend can also declare, most of the youth fund projects and projects, as long as there is a preliminary basis, writing also can obtain high quality declaration. Second, sets up the competition state of mind. To declare, to the best of ability to write each project declaration. The champion horse racing is run out. Once or twice to declare is not project, is very normal. 3 it is to set up the "speculation" mentality. "Speculation" is not to say that walk crooked road, line, but on the basis of seriously study reporting guidelines, pay attention to interdisciplinary integration, development ideas, to find, on the topic and content of innovation. Pay attention to local and holistic consideration; Pay attention to discipline and combination of traditional thinking mode.

(2) pay attention to innovation. Innovation is the new thinking, new inventions and new described as a conceptual process characteristics, mainly including the original theoretical innovation and theory innovation. Young teachers, especially the Dr. Young teachers in colleges and universities, in pay attention to combining with their own original research based on refining outside, still should notice the collaborative innovation, scattered in grafting, forming "" way of doing things. Neither go normal way of doing things, look for some new and different ways to solve the problem, in order to surprise. 1 subject aspects. Seize the problem oriented; Refining scientific problems; Complete the theory of sublimation. Guidance to solve practical topic novel or new Angle of view, by querying the project subject to find calendar year experience, combined with their own experience query literature searching to find feel, stick to the real problems start. Two views. The novel research ideas, innovative. View to support each other between, interlocking, have very strong logic. 3 content. From the aspects of theoretical innovation and innovation from the aspects of object in two aspects, in the old new method, old new problems and new problems to seek breakthrough in the new method.

(3) to highlight their own advantages. Advantage is divided into absolute advantage and comparative advantage, for young teachers in local colleges of Dr. Highlighted more should pay attention to comparative advantage. Highlight your research and previous studies of difference and advantage. Why good answer three: one is why want to do, that topic meaning; Second, why do you want to do now, highlight the opportunity; Three is why do you come, show the host's scientific research advantage.

(4) echocardiography action. Action determine success or failure, the reality of action can be thought possible. One is the need to early action. As solid preparation work, consciously focus on research results. Achievement is not very concentrated, can concise conclusion early successes, seeking can be in favor of the main direction of combination. The second is the specific behavior of project application, need to process the compact. The same declaration process, don't drag. Pay attention to the overall content can mutual echo, mutual support. Three is the scientific research project team to join as early as possible. Their training in the development team, the team progress in developing its own, improve comprehensive quality.

Is shouldering the important task of higher education in local colleges and universities, only to develop scientific research work of all kinds of teachers group potential, inspire teachers' scientific research work enthusiasm, will create the scientific research environment and the innovation ability of the teachers dual combination, can be achieved to good schools and scientific research of sustainable development, effectively promoting the comprehensive competitiveness of the school, the school won a more broad space for the survival and development. In a relatively weak group of the Dr. Young teachers should also pay more attention to process, active participation, perseverance, to dare to try and keep improving the spirit.

\section{REFERENCES}

[1] Wang Jian-guo. Try to talk about in the application of young university teachers' scientific research ability training. Journal of heilongjiang province higher education research. 2010 (9)

[2] Zhou Jing. Young teachers in colleges and universities scientific research current situation analysis and countermeasures research. Journal of research and development management. 2008 (10)

[3] Wu Yufeng. Young teachers in higher vocational colleges in quality and ability of scientific research in the problems and countermeasures. Journal of academic BBS. 2011 (5) 